\title{
Soroprevalência deanticorpos contra o antígeno CagAdo Helicobacter pylori em pacientes com úlcera gástrica na região Norte do Brasil
}

\author{
Seroprevalence of antibodies against the CagA antigen the Helicobacter pylori \\ in patients with gastric ulcer in the North region of Brazil
}

\author{
Luisa Caricio Martins ${ }^{1}$, Tereza Cristina de Oliveira Corvelo1, Henrique Takeshi Oti² e \\ Katarine Antônia dos Santos Barile ${ }^{1}$
}

\begin{abstract}
Resumo O Helicobacter pylori é um agente patogênico largamente distribuído no mundo, estando envolvido no desenvolvimento de várias doenças gastrointestinais. Atualmente a infecção pela cepa virulenta (CagA $\left.{ }^{+}\right)$ do $\mathrm{H}$. pylori é considerado um dos principais fatores etiológicos para o desenvolvimento de ulcerações gástricas. Baseado nessa informação, investigamos a soroprevalência das cepas virulentas entre os pacientes com úlcera gástrica da nossa região, utilizando testes sorológicos para detecção de anticorpos contra o $\mathrm{H}$. pylori $e$ a proteína CagA. Sendo observado que $82 \%$ (45/55) dos pacientes estavam infectados pela cepa virulenta, entre esses 89\% (40/45) apresentaram grau de inflamação aumentado na mucosa gástrica, com denso infiltrado de leucócitos no tecido, o que provavelmente favoreceu a formação das ulcerações gástricas.
\end{abstract}

Palavras-chaves: Helicobacter pylori. Úlcera gástrica. Proteína CagA. Análise sorológica.

Abstract Helicobacter pylori is a pathogenic agent with a worldwide distribution and is involved in the development of many gastrointestinal diseases. Nowadays infection with the virulent strain $\mathrm{CagA}^{+}$of $\mathrm{H}$. pylori is considered one of the main etiological factors in the development of gastric ulcer. Based on this information, we investigated the seroprevalence of virulent strains among patients with gastric ulcer from one region, using serologic tests to detect antibodies against $\mathrm{H}$. pylori and CagA protein. Infection by the virulent strain was found in $82 \%(40 / 55)$ of the patients, and among these, 89\% (40/45) presented an increased degree of inflammation in the gastric mucosa, with a dense infiltration of leukocytes in the tissue, which probably favored the formation of gastric ulcer. We concluded that the presence of the virulent strain is related to the development of an increased inflammation in the gastric mucosa.

Key-words: Helicobacter pylori. Gastric ulcer. CagA protein. Serological analyses.

A úlcera gástrica é geralmente única, predomina na pequena curvatura do antro, próximo a incisura angular, em região adjacente à mucosa secretora de ácido. Está relacionada à deficiência dos fatores defensivos da mucosa, não sendo capazes de proteger o epitélio contra os efeitos corrosivos do ácido e pepsina ${ }^{9}$. Parece que, o maior responsável pela diminuição da resistência da mucosa ao ataque do ácido é a inflamação crônica ${ }^{6}$. Postula-se então, que o $H$. pylori associado à gastrite, seriam os agentes responsáveis pela diminuição da defesa da mucosa ${ }^{6}$. A infecção pelo $H$. pylori leva a um processo inflamatório agudo ou crônico da mucosa gástrica $^{369}$. Dessa forma, as úlceras gástricas ocorrem na presença de gastrite crônica superficial ou atrófica, desenvolvendo-se no limite do processo inflamatório ${ }^{39}$.

$\mathrm{O} H$. pylori produz várias proteínas que parecem mediar ou facilitar seus efeitos deletérios sobre a mucosa gástrica. Atualmente, tem sido bastante ressaltada a associação da citotoxina $\operatorname{Cag} A \operatorname{com}$ aumento da inflamação gástrica e consequentemente, com quadros clínicos mais graves. As cepas virulentas $\left(\mathrm{Cag} A^{+}\right)$induzem forte processo inflamatório, com denso infiltrado de neutrófilos, que causam graves danos à mucosa gástrica ${ }^{1013}$.

A literatura sugere que a soroprevalência para o antígeno $\operatorname{Cag} A$ do $H$. pylori em adultos com úlcera

\footnotetext{
1. Laboratório de Imunogenética do Departamento de Genética da Universidade Federal do Pará, Belém, PA. 2. Departamento de Endoscopia do Hospital Ofir Loiola, Belém, PA.

Orgão financiador: Capes e FUNTEC

Endereço para correspondência: Dra Luisa Caricio Martins. Trav. Mauriti 3269/402B, Marco, 66095-360 Belém, PA

Tel: $5591211-1568$, ramal 28

e-mail: lu-caricio@bol.com.br ou abdala@amazon.com.br

Recebido para publicação em 21/9/2001.
} 
gástrica está aumenta, existindo uma associação entre a presença do $\operatorname{Cag} A$ e o risco aumentado de desenvolver úlcera peptica e câncer gástrico ${ }^{610}$.

Estudos sorológicos têm demonstrado que pacientes com úlcera péptica e tumor gástrico são mais freqüentemente infectados por cepas virulentas ${ }^{10}{ }^{13}$, cerca de $60 \%$ a $100 \%$, sugerindo que o gene CagA pode ser considerado um marcador genotípico e fenotípico para linhagens virulentas ${ }^{5} 718$.

Com base no descrito acima, esse estudo pretende contribuir para esclarecer a associação entre as cepas Tipo I e o desenvolvimento da úlcera gástrica, mediante a análise da resposta imunológica humoral e da prevalência do gene $C a g A$ em pacientes com úlcera gástrica.

\section{MATERIAL E MÉTODOS}

O estudo compreende um total de 55 pacientes (41 homens , 14 mulheres, faixa etária de 28-80, média aritmética $=53,59$ e desvio padrão $=12,63$ ) com úlcera gástrica, segundo laudo endoscópico realizado no Serviço de Endoscopia do Hospital Ofir Loiola, localizado na região metropolitana de Belém, Pará. Foram coletadas amostras pareadas de sangue e biopsia gástrica, sendo selecionados preferencialmente os pacientes que nunca haviam realizado tratamento para erradicação do $H$. pylori. $O$ estudo foi aprovado pelo Comitê de Ética do Núcleo de Medicina Tropical da UFPA, processo $n^{\circ}$ 009/00.

À todos os indivíduos foi empregado um questionário para a obtenção de dados epidemiológicos, e solicitado, através de um termo de consentimento livre e esclarecido, a autorização para obtenção das amostras e realização da pesquisa.

Detecção sorológica de anticorpos da classe lgG anti-H. pylori específicos. Amostras de soro foram testadas para anticorpos contra o $H$. pylori, através de um ensaio de Hemaglutinação indireta, de acordo com as instruções de uso recomendadas pelo fabricante (Viva diagnostika, Hürth, Alemanha).

As amostras que obtiveram resultados negativos ou inconclusivos na técnica citada acima, foram testadas para anticorpos sistêmicos da classe lgG $H$. pylori específicos através de um ensaio imunoenzimático (ELISA), usando o kit Immunocard H. pylori (Meridian Diagnostics, Inc, USA).
Detecção de anticorpos IgG Anti-Cag A. Foi determinada por um ensaio imunoenzimático (ELISA), baseado nos recombinantes $H$. pylori Cag $A$ (Helicobacter p 120 EIA, VIVA Diagnostica, Hürth, Alemanha).

Biópsias gástricas. As biópsia gástricas foram coletadas durante a realização do exame de endoscopia digestiva alta, sendo retiradas das áreas de borda de lesão e perilesão.

Para análise histopatológica das biópsia gástricas foi utilizada a coloração Hematoxilina-Eosina (HE). Nos parâmetros histopatológicos foi utilizado a classificação de Sidney. A presença de inflamação crônica (infiltrados celular mononuclear e neotrofílico no tecido) foram graduada numa escala de 0 a 3, representando, ausente (0), leve (1), moderado (2), acentuado (3).

Para a detecção do $H$. pylori foi utilizado a coloração Gram modificado e microscopia óptica convencional, identificando a bactéria mediante suas características morfológicas, forma curva e espiralada, e coloração azul intensa.

Análise estatística. Foram empregados testes estatísticos adequados para detectar ou não diferenças entre os grupos objeto de estudo. O programa de computação utilizado foi o Bioestat $2.0^{2}$, com o emprego dos testes do qui-quadrado $\left(c^{2}\right)$, teste exato de Fisher, entre outros. A significância estatística foi aceita ao nível 95\%.

\section{RESULTADOS}

Foram analisadas 55 amostras pareadas de biopsia gástrica e sangue, além das respectivas informações epidemiológicas fornecidas pelos pacientes através do questionário informativo.

Em relação ao sexo, observamos um predomínio do sexo masculino, 74\% (41/55), sendo que $47 \%$ (26/ 41) tinham idade acima de cinqüenta anos. O sexo feminino representa $26 \%$ (14/55) da amostra, onde $13 \%$ (7/14) tinham idade acima de cinqüenta anos.

Os pacientes eram portadores de úlcera gástrica, baseado no laudo endoscópico, sendo que 76\% (42/ 55) apresentavam ulceração na região antral e 24\% (13/ 55) apresentavam ulceração na região do corpo gástrico. Em relação aos laudos histopatológicos obtivemos que $96 \%$ (53/55) dos pacientes apresentavam gastrite crônica e 4\% (2/55) com carcinoma avançado ulcerado, com grau de inflamação variando de leve, $22 \%(12 / 55)$, moderado $47 \%$ (26/55), acentuado, 31\% (17/55).

Diferenças estatisticamente não significativas foram observadas quando compara-se o padrão alimentar, o hábito de vida e o consumo de medicamentos, principalmente AINES e AAS (Antiinflamatório não esteróides e acido acetil salicílico), em relação ao grau de inflamação no tecido gástrico dos pacientes.

A observação do padrão dietético mostrou que $80 \%$ (44/55) dos pacientes faziam uso excessivo de sal, com ingestão elevada de gordura em sua alimentação diária. Adicionalmente, quando comparamos o grau de inflamação do tecido gástrico ao número de refeições que os pacientes fazem ao dia, observamos uma associação estatisticamente significativa $(G=9.4098$, 
$p=0.0281)$, onde $60 \%(33 / 55)$ dos pacientes se alimentavam duas ou menos vezes ao dia, destes $36 \%$ (20/55) apresentavam grau de inflamação moderado, $24 \%(10 / 55)$ com grau acentuado.

Em relação às condições de habitação, a correlação entre a prevalência da infecção pelo $H$. pylori e a ausência de infra-estrutura adequada de saneamento, também apresentou-se estatisticamente não significante.

$\mathrm{OH}$. pylori foi detectado sorologicamente em $93 \%$ $(51 / 55)$ dos pacientes, sendo que $82 \%$ (45/55) foram positivos para a cepa virulenta (Tabela 1). Quanto à

Tabela 1- Relação entre a infecção pelo H. pylori e a presença da cepa virulenta CagA nos pacientes com úlcera gástrica.

\begin{tabular}{lccc} 
& \multicolumn{2}{c}{ Cepa virulenta CagA } & \\
\cline { 2 - 3 } Infecção pelo H.pylori & positivo & negativo & Total \\
\hline Positivo & 45 & 6 & 51 \\
Negativo & 0 & 4 & 4 \\
\hline Total & 45 & 10 & 55
\end{tabular}

Fisher, $p=0,0006$

associação da infecção pelo microorganismo e o grau de inflamação do tecido gástrico, verificou-se uma correlação estatisticamente significativa entre a presença da infecção pela cepa virulenta do $H$. pylori e o grau de inflamação moderado à acentuado (Tabela 2). Também

Tabela 2 - Distribuição dos diferentes níveis de inflamação encontrados no tecido gástrico dos pacientes associado ao diagnóstico sorológico para detecção da infecção pelo $\mathrm{H}$. pylori e da cepa CagA.

\begin{tabular}{|c|c|c|c|}
\hline \multirow[b]{2}{*}{ Sorologia H. pylori } & \multicolumn{2}{|r|}{ Grau de inflamação } & \multirow[b]{2}{*}{ Total } \\
\hline & leve & moderado à acentuado & \\
\hline $\mathrm{Hp}^{+} \mathrm{CagA}^{+}$ & 5 & 40 & 45 \\
\hline $\mathrm{Hp}^{+} \mathrm{CagA}$ & 4 & 2 & 6 \\
\hline Hp CagA & 3 & 1 & 4 \\
\hline Total & 12 & 43 & 55 \\
\hline
\end{tabular}

$\mathrm{G}=14.1739 p=0.0023$

observamos uma associação estatisticamente significativa entre a presença da cepa virulenta e o relato de recidivas das ulcerações gástricas (Tabela 3 ).

Tabela 3 - Distribuição do resultado sorológico para detecção da infecção por $\mathrm{H}$. pylori e da cepa CagA associado aos relatos dos pacientes de ocorrências anteriores de ulcerações gástricas.

\begin{tabular}{lcccc}
\hline & \multicolumn{3}{c}{ Sorologia Helicobacter pylori } & \\
\cline { 2 - 4 } Recidivas & $\mathrm{Hp}^{+} \mathrm{CagA}^{+}$ & $\mathrm{Hp}^{+} \mathrm{CagA}$ & $\mathrm{Hp} \mathrm{CagA}$ & Total \\
\hline Ausente & 10 & 4 & 3 & 17 \\
Presente & 35 & 2 & 1 & 38 \\
\hline Total & 45 & 6 & 4 & 55 \\
\hline
\end{tabular}

$\mathrm{G}=8.2104 \mathrm{p}=0.0264$

Quando comparamos os resultados obtidos na pesquisa do $H$. pylori pelo método sorológico e histológico, observamos, pelo método sorológico, uma prevalência de $93 \%(51 / 55)$ dos pacientes infectados pelo $H$. pylori, diferindo significativamente dos $76 \%$ (38/ 55) observado pelo método histológico (Tabela 4).
Tabela 4 - Comparacão entre os resultados obtidos no diagnóstico da infecção pelo $\mathrm{H}$. pylori através dos métodos sorológico e histológico.

\begin{tabular}{|c|c|c|c|}
\hline \multirow[b]{2}{*}{ Infecção por H. pylori } & \multicolumn{2}{|c|}{ Método de diagnóstico } & \multirow[b]{2}{*}{ Total } \\
\hline & sorológico & (Gram modificado) & \\
\hline Positivo & 51 & 38 & 89 \\
\hline Negativo & 4 & 12 & 16 \\
\hline Total & 55 & 50 & 105 \\
\hline
\end{tabular}

\section{DISCUSSÃO}

Desde que o $H$. pylori foi cultivado em 1983, tem havido grande interesse em seu estudo, objetivando descobrir sua verdadeira função no desenvolvimento das doenças gastrointestinais, bem como na descoberta dos melhores meios de diagnóstico ${ }^{8}$.

O diagnóstico da infecção pelo $H$. pylori foi obtido mediante a utilização de métodos sorológicos e histológico (Gram modificado), nos pacientes portadores de úlcera gástrica. De acordo com os resultados deste estudo, a taxa de infecção pelo $H$. pylori obtida pelo método sorológico foi de 93\%, diferindo significativamente do valor de $76 \%$ detectado no exame histopatológico pela coloração de Gram modificado (Tabela 4). Este valor de positividade observado pelo método histopatológico está dentro dos valores esperados para a população de Belém ${ }^{115}$.

Mendonça et a ${ }^{11}$ obtiveram resultados similares na comparação entre esses dois métodos, onde a sensibilidade do método sorológico se mostrou superior a do teste histológico pela coloração do Gram modificado. Alguns estudos têm demonstrado que o padrão de colonização do $H$. pylori na mucosa gástrica dar-se de forma irregular, onde várias vezes pode ocorrer a retirada de biópsias gástricas de regiões não colonizadas, resultando em falsos negativos pelo método histológico ${ }^{11} 1217$. O mesmo pode ocorrer em pacientes com metaplasia intestinal, onde é incomum a presença da bactéria, pois as características deste tipo de epitélio não favorece o crescimento da mesma ${ }^{1617}$.

Neste estudo, $70 \%$ dos pacientes apresentavam baixo nível sócio econômico e saneamento básico inadequado, o que representa um fator crucial na exposição ao $H$. pylori. Outros trabalhos constataram uma alta prevalência da infecção pelo $H$. pylori entre os indivíduos que vivem em condições inadequadas de higiene e saneamento ${ }^{78}$.

Em relação aos sexos, não temos conhecimento de nenhum trabalho que mostre uma associação entre os sexos e a infecção pelo $H$. pylori. Entretanto alguns estudos $^{612}$ têm demonstrado a taxa mais elevada de homens entre os portadores de úlcera péptica. Esse fato pode ser explicado pela participação de outros fatores ambientais como o estilo de vida, onde normalmente o sexo masculino se encontra mais exposto ao estresse e ao consumo de álcool e fumo. 
De acordo com os resultados obtidos, observamos que $80 \%$ dos pacientes faziam uso freqüente de álcool, fumo, medicamentos e possuíam uma dieta rica em sal e gorduras. Räihä et $a^{15}$ descreveram uma alta freqüência de pacientes com úlcera péptica que faziam uso diário de álcool, fumo, além de um padrão alimentar rico em sal e gordura e pobre em fibras e antioxidantes.

No presente estudo, observamos que $82 \%$ dos pacientes com úlcera gástrica eram sororreativos para a cepa tipo I (Tabela 1). Lin et a/ ${ }^{10}$ utilizando testes moleculares, obteveram resultados similares, onde $82,5 \%$ dos subtipos da $H$. pyloriisolados de pacientes com ulcera péptica da população de Taiwan expressavam o gene CagA. Outros estudos sorológicos vêm descrevendo uma alta prevalência da cepa virulenta entre os pacientes com úlcera peptica e câncer gástrico ${ }^{1013}$.

Histologicamente, $79 \%$ (43/55) da amostra apresentou grau de inflamação de moderado à acentuado, caracterizado pela presença de denso infiltrado celular mononuclear e neutrofílico na mucosa gástrica, neste grupo 93\% (40/43) dos pacientes estavam infectados pela cepa virulenta (Tabela 2).
Censini et $a^{A}$ descreveram que as cepas virulentas $\left(\mathrm{Cag} A^{+}\right)$estimulam a produção de substâncias quimiotáticas, como IL-8 e IL-6, que atraem e ativam neutrófilos e outras células inflamatórias. Essa resposta inflamatória aumentada e intermitente, causa agressão à mucosa gástrica, o que favoreceria ao aparecimento das ulcerações gástricas.

Outra associação observada no presente estudo, foi a relação entre a presença da cepa virulenta e as recidivas das ulcerações gástricas (Tabela 3), onde $64 \%$ dos pacientes com úlcera gástrica e portadores da cepa virulenta relataram ocorrências anteriores de úlcera gástrica. Esses pacientes foram somente submetidos ao tratamento das ulcerações gástricas, não realizaram tratamento de erradicação do $H$. pylori. Esse fato pode explicar as recidivas das úlceras gástricas, pois estes indivíduos tinham uma infecção persistente pela cepa virulenta. Alguns trabalhos têm demonstrado uma diminuição das recidivas ulcerosas quando o paciente realiza tratamento de erradicação do H. pylori². Reforçando a necessidade de uma melhor avaliação sobre o emprego de um tratamento de erradicação deste microorganismo.

\section{REFERÊNCIAS BIBLIOGRÁFICAS}

1. Aguiar DCF. Correlação da expressividade dos antígenos ABH Lewis com a gastrite crônica e alterações pré-neoplásicas da mucosa gástrica. Tese de Mestrado. Belém, Universidade Federal do Pará, Museu Paraense Emílio Goldi, Empresa Brasileira de Pesquisa Agropecuária, 2001.

2. Ayres M, Ayres MJ, Ayres DL, Santos AS. Bioestat 2.0 Aplicações estatísticas nas áreas das ciências biológicas e médicas. Sociedade Civil Mamirauá Ministério de Ciências e Tecnologia- Conselho Nacional de Desenvolvimento Científico e Tecnológico, 2000.

3. Blaser MJ. Helicobacter pylori and the pathogenesis of gastroduodenal inflammation. Journal of Infectious Diseases 161: 626-633, 1990.

4. Censini S, Lange C, Xiang Z, Crabtree EJ, Ghiara P, Bodovsky M, Rappuoli R, Covacci A. CagA, a pathogenicity isolate of Helicobacter pylori, encodes type I- specific and diseaseassociated virulence factors. Proceedings of the National Academy of Science 93:14648-14653, 1996

5. Censini S, Stein M, Covacci A. Cellular responses induced after contact with Helicobacter pylori. Current opinion in Microbiology 4: 41-48, 2001.

6. Chehter L. Úlcera Péptica Gastroduodenal. Sinopse de Gastroenterologia- Universidade Federal de São Paulo 1:14-18, 1999.

7. Covacci A, Telford LJ, Giudice DG, Parsonnet J, Rappuoli R Helicobacter pylori virulence and genetic geography. Science 284: 1328-1333, 1999.

8. Dunn BE, Cohen H, Blaser MJ. Helicobacter pylori. Clinica Microbiology Reviews 10: 720-741, 1997.

9. Friedman LS, Peterson WL. Úlcera Péptica e distúrbios relacionados. In: Harrison TR. Medicina Interna. Rio de Janeiro, McGraw-Hill, p.1699-1721, 1998.
10. Lin CW, Wu SC, Lee SC, Cheng KS. Genetic analysis and clinical evaluation of vacuolating cytotoxin gene $A$ and cytotoxinassociated gene A in Taiwanese Helicobacter pylori isolates from peptic ulcer patients. Scandinavian Journal of Infectious Diseases 32: 51-57, 2000.

11. Mendonça CA, Mendes VVC, Amorim VL. H. pylori: Estudo comparativo entre os métodos diagnósticos histopatológico, Gram e IgG. Gastrenterologia Endoscopica Digestiva 16: 124-127, 1997.

12. National Institutes of Health Consensus Conference. Helicobacter pylori in peptic ulcer disease. The Journal of the American Medical Association 272: 65-69, 1994.

13. Queiroz MMD, Mendes NE, Carvalho STA, Rocha AG, Oliveira RMA; Soares FT, Santos A, Cabral ADMM, Noqueira FMMA. Factors associated with Helicobacter pylori infection by a CagApositive strain in children. The Journal of Infections Diseases, 181: 626-630, 2000.

14. Räihä I, Kemppainen H, Kaprio J, Kosken VUO, Sourander L. Lifestyle, stress, and genes in peptic ulcer disease. Archives International Medical 158: 698-704, 1998.

15. Sagica FES. Perfil imunohistoquímico da mucosa gástrica no desenvolvimento do câncer gástrico. Tese de Mestrado. Universidade Federal do Pará, Museu Paraense Emílio Goldi, Empresa Brasileira de Pesquisa Agropecuária. Belém, 2000.

16. Shimoyama T, Crabtree JE. Bacterial factors and immune pathogenesis in Helicobacter pylori infection. An International Journal of Gastroenterology and Hepatology- Gut, 43: S2-S5, 1998.

17. Warren JR. Gastric pathology associated with Helicobacter pylori. Gastroenterology Clinics 29: 705-715, 2000.

18. Williams PM, Pounder MA. Helicobacter pylori: From the benign to the malignant. The American Journal of Gastroenterology 94 (supl II): 115-165, 1999. 